\title{
Innovation Indicators and Growth in the United Arab Emirates
}

\author{
*Abdelkader Mazouz ${ }^{(1)}$, Loay Alnaji (2), Riadh Jeljeli ${ }^{(3)}$, \\ Fayez Al-Shdaifat ${ }^{(4)}$
}

\section{${ }^{(1,3,4)}$ Al Ain University of Science and Technology, UAE

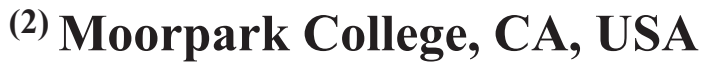 \\ *abdelkader.mazouz@aau.ac.ae}

\begin{abstract}
Innovation and leadership are so closely interrelated that leadership thinks of the future and innovation is the fruit of leadership in the future. This paper aims to determine whether leadership leads to innovation. Under visionary leadership, innovation can progress and bear fruit. An appropriate framework to provide a platform for innovation is a necessary condition and requires the appropriate leadership to guide its flow in that direction. Competency for innovation arrises from two main cores: interior and exterior. The exterior core has three components: culture, resources, and habitat; the interior core also has three components: knowledge, attitude, and imagination. The components of, the exterior core, relates to the outside world and one's surroundings whereas the components of the interior core relate to us as individuals. The job of leadership is to create a platform wherein the inner forces synchonize with the outside forces. This paper uses Seelig's Innovation Engine, model to measure innovation progress in multiple industries in the Gulf region and to identify the most innovative industries. A survey, distributed to leaders in several major industries, was collected, analyzed, and presented.
\end{abstract}

Keywords: Innovation Engine; Corporate Entrepreneurships; Innovation Leadership.

\section{Introduction}

Establishing a competitive edge is becoming a highly complex issue. Companies must think ahead and plan rigorously, even in United States, in European countries, and now in the United Arab Emirates (UAE). Most organizations focus on how to compete now, using indicators responding to problems arising now. Through industry analysis, we observe that to gain a competitive edge through customer service, most of the time an industry must outperform the competition in two areas:

1. The company tailors the product to the individual needs of customers.

2. The company tailors the customer service to individual needs.

Survival requires planning ahead and developing a meticulous innovation and implementation plan. Innovation matters as it is the only way to survive over time. Questions arise: Where should organizations concentrate? What are the key indicators to use to survive? Some industry 
giants such as General Electric (GE), Dupont, and Procter and Gamble have successful products and competent people; usually they have effective leaders. More importantly, they have a fundamental reason for their success: Innovation Management.

Managing innovation was the key to their success, following the often identified S curve of survival shown in Figure 1. The "S" curve model shows how the innovation process starts, accelerates, plateaus, and declines, requiring organizations to develop new technologies. For instance, GE, in the early 1900s, perfected Edison's most notable invention: the industrial laboratory. GE brought a management discipline to the chaotic process of scientific discovery, which translated in generating more patents than any other U.S. organization. Much of their current successes can trace to the extraordinary accomplishment of managing scientific discovery. Another example is Dupont, It played a major role in the development of capitalbudgeting by techniques when it started using return on investment (ROI) calculations in the beginning of the last centuey 1903. A few years, later the company developed performance standard of its several product departments; thus, because of these innovations, Dupont became a U.S. Industrial giant.

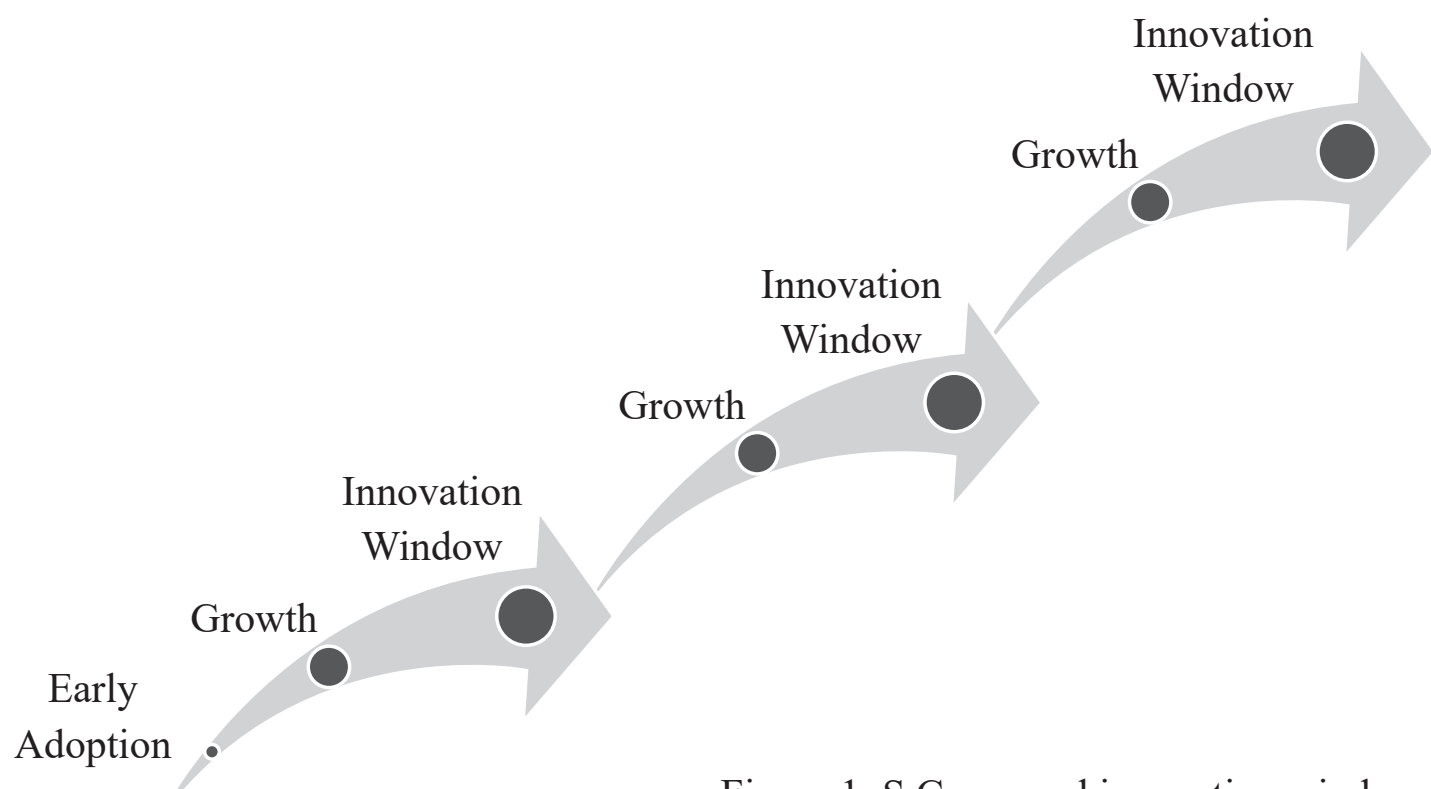

Figure 1: S Curve and innovation window.

Management innovation creates a long-lasting advantage. Innovation is systematic, encompassing a range of processes and methods as part of an ongoing program of invention, where progress compounds over time. Entrepreneurship is the fruit of innovation. Corporate entrepreneurship generally refers to the development of new ideas and opportunities in an established business that will directly lead to the improvement of organizational profitability and an enhancement of competitive position. Corporate entrepreneurship is crucial for large companies, enabling them to take risks and innovate, driving leaders and teams toward an increased level of corporate enterprise.

The benefits obtained through innovation sets the stage for leadership continuity. Nowadays, among the main tasks of the organization leader is the fostering of an environment in which entrepreneurial thinking is encouraged and in place. Promoting innovation and corporate 
entrepreneurship, leaders strive to build trust, embracing the risk to fail and inspiring their team to take similar calculated risks.

ASSESSMENT TRIFECTA: THE LINK

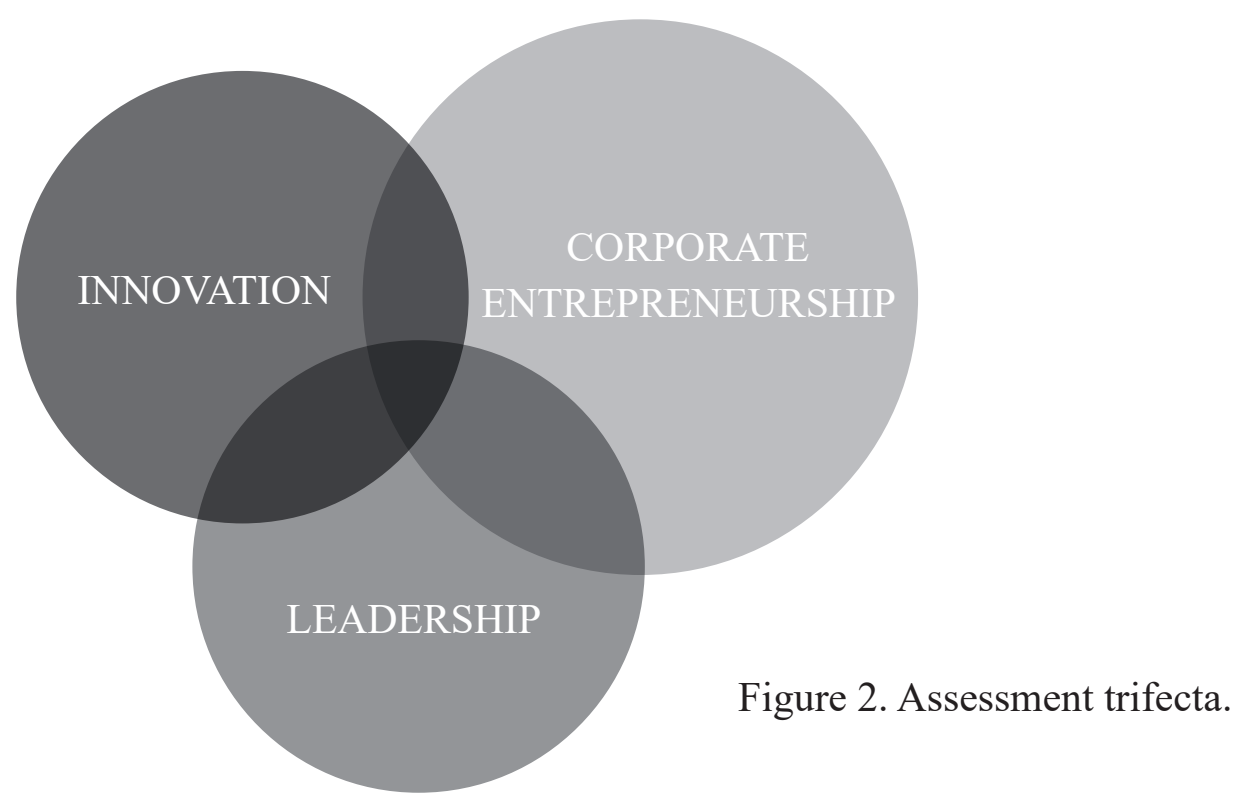

In considering the growth of any organization, three parameters play a major role, innovation management, entrepreneurship, and leadership. Any organization aiming to survive needs to operationalize the three parameters. The success of management innovation is the link between innovation, entrepreneurship, and leadership, identified as the trifecta assessment depicted in Figure 2. In the process of moving from ideation to product launch, these three major areas must align to increase the probability of success of a new idea. This article aims is to discern if an organization has the necessary attributes to maintain an innovation platform and embrace a corporate-entrepreneurship culture, when led by appropriate leadership. A sample from UAE organizations is the tested environment.

\section{Literature Review}

Innovation, a word derived from the Latin word novus, is defined differently, depending on where it is used (Katz \& Du Preez, 2008). For some, innovation means a new idea or method, or even device (Gopalakrishnan \& Damanpour, 1994, p. 95). For others, innovation means the introduction of new processes into a system (Schumpeter, 1934). Innovation may mean development of new corporate processes and structures as well as methods and processes (Bornemann et al., 2003). Abou-Zeid and Cheng (2004 provided a comprehensive definition of innovation by dividing it into two parts: the first views innovation as conceiving a new product whereas the second views innovation as inventing something new.

Culture is key for the development of innovation and entrepreneurship. Using 718,758 observations collected from the Global Entrepreneurship Monitor database, Turró, Urbano, and Peris-Ortiz (2014) found a strong relationship between environmental variables such as living 
in an entrepreneurial culture. Procedures needed to create a new business can significantly affect corporate entrepreneurship. In any culture, leadership plays a major role in supporting innovation. Certain leadership behaviors can support innovation (Yuk1, 2002). Innovation can only occur through leadership (Sarros, Cooper \& Santora, 2008) and the transformational leadership style is key to supporting innovation (Ancona \& Caldwell, 1987). A leader with a vision can create a culture that supports innovation (Damanpour \& Schneider, 2006).

A strong relationship exists between innovation and knowledge. In their paper, Cantner, Joel, and Schmidt (2011) paired companies using knowledge management to similar companies that did not use knowledge-management techniques. They found that those using knowledge-management techniques performed better in "higher than average shares of turnover with innovative products" (p. 1). Investigating the relationship among knowledge-sharing capability, absorptive capability, dynamic capability, and organizational innovation performance, Pai and Chang (2013) found a positive relationship between knowledge-sharing capabilities and knowledge performance. Surveying 103 companies in Turkey on innovation and knowledge management, Kör and Maden (2013) found that knowledge-management processes relate positively to innovation. Attitude toward implementing strategies and new techniques that support innovation is important for a culture of innovation to succeed (Frambach \& Schillewaert, 2002). The assessment of the right balance between innovation and resources depends on the assessor.

Although some believe small firms cannot innovate because they cannot properly use their resources (Teece, 1986), others state that the ability of small firms to properly use their resources helps them be more innovative than larger organizations (Arrow, 1962). Using the dynamic capability approach, Pavlou and El Sawy (2006) demonstrated the impact of IT resources on new-product development. Similarly, Klingebiel and Rammer (2011) not only investigated the importance of resources for innovation, but the importance of properly managing and allocating them. Furthermore, Klingebiel and Rammer stated that "breadth in resource allocation increases innovation performance, more so than the amount of resources devoted to each project" (2011, p. 1). Other researchers explored various resource attributes on organizational innovation, such attributes as resource exchanges (Hargadon \& Bechky, 2006), resource availability (Choi \& Chang, 2009), and resource diversity and quality (Srivastava \& Gnyawali, 2011). Innovation and creativity have become key factors for an organization's success.

For companies to develop innovative ideas and products, they must first cultivate new creative ideas (Amabile, 1988; Day, 1994; Shalley \& Zhou, 2008), then implement the new ideas (Shalley \& Zhou, 2008). Some researchers noted that the boundaries between innovation and creativity are unclear (Anderson, Potočnik, \& Zhou, 2014). 


\section{Approach}

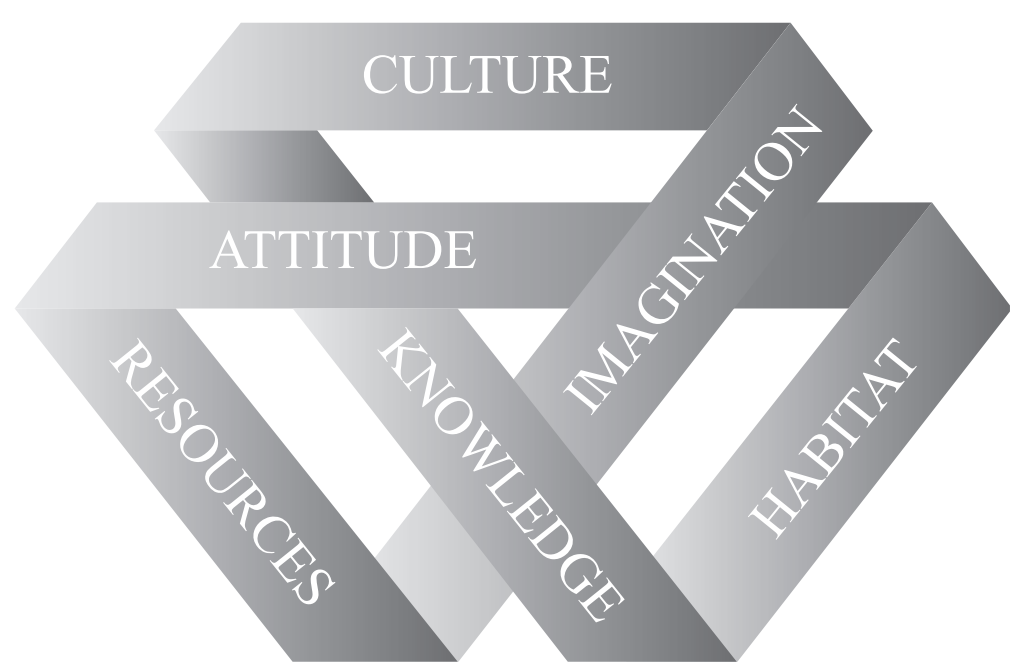

Figure 3. Tina Seelig Innovation Engine ${ }^{(1)}$

Looking at the growth of any organization, three parameters play a major role, namely, Innovation Management, Entrepreneurship and Leadership. Any organization aiming at surviving needs to sink the three parameters. The success of management innovation is the link between Innovation, Entrepreneurship and Leadership identified as the Trifecta Assessment. Looking at the process from Ideation to Product launch, these three major areas are necessary to be in place and be in sink to increase the probability of success of new ideas.

Tina Seelig described it best by providing to the world the Innovation Engine and has identifying the components that make the innovation engine. Figures 3. shows the Tina Seelig Innovation Engine. These parameters are divided into two sets: the inside and the outside. The inside framework is what an organization is. The world has to provide in order to derive the next three which describe the outside framework. The inside framework is defined by three components Culture, Habitat and Resources, while Knowledge, Attitude and Imagination define the outside framework.

Innovation, corporate entrepreneurship, and leadership are a philosophy and a group of techniques that combine different leadership styles to influence employees to produce creative ideas, products, and services that are highly marketable by setting a new market trend. Innovation leadership is needed to avoid the struggles of organizations whereas entrepreneurial leadership means organizing a group of people to achieve a common goal using proactive entrepreneurial behavior by optimizing risk, innovating to take advantage of opportunities, taking personal responsibility and managing change in a dynamic environment for the benefit of an organization. An organization aims to provide the suitable platform to launch corporate entrepreneurship and sustain a successful new product or service with the appropriate leadership style or styles.

1 Used with permission from Dr. Seelig 


\section{Methodology}

Researchers have used the Kuratko Corporate Entrepreneurship Assessment Instrument (CEAI) entrepreneurship survey, focused on five major components comprising 48 questions. Through the series of questions, when tallied aligned with the Kuratko recommendations, a threshold of three indicates if an organization has the necessary attributes to be entrepreneurial. The issue in this case is to examine more deeply, asking if an organization has the attributes to be innovative and to be entrepreneurial, and has the appropriate leadership to launch the new product or service in the marketplace with a high probability of being able to sustain growth in the marketplace.

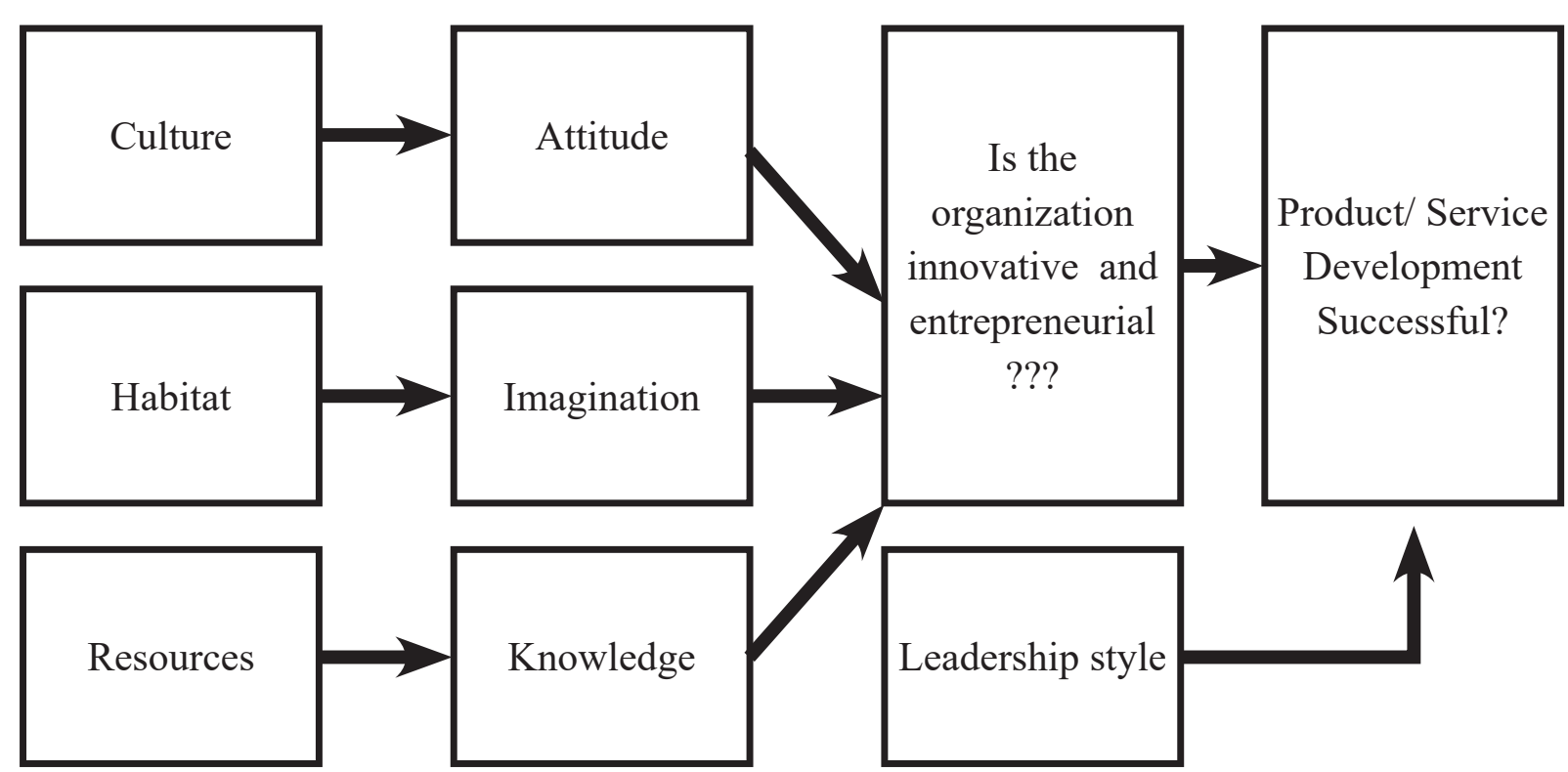

Figure 4. Assessment trifecta model.

The following scenario is best shown in Figure 4. This figure depicts the link between innovation and corporate entrepreneurship. The first block shows what an organization can provide as the innovation platform. The second block shows the basis for an individual in an organization to be creative and innovative. When the two blocks are in place and synchronous, ideas will emerge; the organization has set a creative mode once the first two blocks are fulfilled. The creative mode activates the corporate-entrepreneurship mode. To sustain and grow, the appropriate leadership style will fulfill the growth and sustainability of the new product or service.

The CEAI features 48 Likert-style questions used to assess antecedents of innovative behavior. The instrument examines five stable antecedents of middle-level managers' entrepreneurial behaviors:

1. Management support for corporate entrepreneurship: the willingness of top-level managers to facilitate and promote innovative behavior, including championing innovative ideas and providing necessary resources.

2. Work discretion/autonomy: top-level managers' commitment to tolerate failure, provide decision-making latitude and freedom from excessive oversight, and delegate authority and responsibility. 
3. Reward/reinforcement: development and use of systems that reward based on performance, highlight significant achievements, and encourage pursuit of challenging work.

4. Time availability: evaluating workloads to assure time to pursue innovations and structure jobs to support efforts to achieve short- and long-term organizational goals.

5. Organizational boundaries: precise explanations of outcomes expected from organizational work and development of mechanisms to evaluate, select, and use innovations.

The CEAI contains 19 questions on managerial support for corporate entrepreneurship, whereas the second leg pertains to how an employee explores the freedom to decide and be autonomous in making decisions. The third leg looks at rewards and reinforcement whereas the fourth leg focuses on time availability, time constraints, and time to develop new ideas. Organization boundaries is the fifth leg, considering procedures, written rules, and limits.

First, we analyze the correlation between the Kuratko five components and Seelig Innovation Engine components. The clustering is as follows: the 48 variables identified in the CEAI set are grouped into the six components of the Innovation Engine. We gathered a data set from domestic organizations in the UAE. The grouping is as follows, based on factor analysis conducted using partial least squares (PLS).

For the factor analysis, we grouped the 48 questions into six major variables identified in the Innovation Engine. The grouping was based on the varimax technique in PLS software. As shown in the following tables, each Innovation Engine component shows a minimum degree of adaptation of the corresponding statements of at least $60 \%$, except for three statements. As for attitude, the statements "During the past three months, my workload kept me from spending time on developing new ideas," "I feel that I am always working with time constraints on my job," and "My coworkers and I always find time for long-term problem solving" show lower correlation and the same idea was expressed with habitat with the following two statements: "I almost always get to decide what I do on my job" and "I have much autonomy on my job and am left on my own to do my own work." Culture expressed low correlation only with one statement: "The rewards I receive are dependent upon my work on the job."

Tables 1, 2, and 3 show the results from the factor analysis varimax technique, grouping the six Innovation Engine components with the 48 questions from CEAI. Table 4 shows results without the correlation coefficient. We noticed that one component of the Innovation EngineImagination - did not correlate with any variable from the 48 questions. 
Table 1

\begin{tabular}{|c|c|c|l|l|l|c|}
\cline { 2 - 7 } \multicolumn{1}{c|}{} & Resources & Attitude & Culture & Habitat & Imagination & Knowledge \\
\hline KNOW41 & & & & & & $\mathbf{0 . 6 1 3}$ \\
\hline KNOW42 & & & & & & $\mathbf{0 . 6 9 9}$ \\
\hline KNOW43 & & & & & & 0.803 \\
\hline KNOW44 & & & & & & 0.735 \\
\hline KNOW45 & & & & & & $\mathbf{0 . 6 4 2}$ \\
\hline KNOW46 & & & & & & $\mathbf{0 . 5 9 5}$ \\
\hline KNOW47 & & & & & 0.853 \\
\hline KNOW48 & & & & & & 0.785 \\
\hline RESO10 & 0.805 & & & & & \\
\hline RESO11 & 0.873 & & & & & \\
\hline RESO12 & 0.795 & & & & & \\
\hline RESO13 & 0.709 & & & & & \\
\hline RESO14 & 0.775 & & & & & \\
\hline RESO15 & 0.787 & & & & & \\
\hline RESO16 & 0.733 & & & & & \\
\hline
\end{tabular}

Table 2

Factor Analysis Results for Attitude and Culture

\begin{tabular}{|c|c|c|l|l|l|l|}
\cline { 2 - 7 } \multicolumn{1}{c|}{} & Resources & Attitude & Culture & Habitat & Imagination & Knowledge \\
\hline ATTIT29 & & 0.708 & & & & \\
\hline ATTIT30 & & 0.742 & & & & \\
\hline ATTIT31 & & $\mathbf{0 . 6 4 3}$ & & & & \\
\hline ATTIT32 & & 0.808 & & & & \\
\hline ATTIT33 & & $\mathbf{0 . 6 4 2}$ & & & & \\
\hline ATTIT34 & & $\mathbf{0 . 6 5 4}$ & & & & \\
\hline ATTIT35 & & $\mathbf{0 . 6 6}$ & & & & \\
\hline ATTIT36 & & $\mathbf{0 . 5 2 1}$ & & & & \\
\hline ATTIT37 & & $\mathbf{0 . 6 8 6}$ & & & & \\
\hline ATTIT38 & & $\mathbf{0 . 6 0 4}$ & & & & \\
\hline ATTIT39 & & $\mathbf{0 . 4 1 4}$ & & & & \\
\hline ATTIT40 & & $\mathbf{0 . 6 8 4}$ & & & & \\
\hline CULT1 & & & 0.862 & & & \\
\hline CULT2 & & & 0.911 & & & \\
\hline CULT3 & & & 0.867 & & & \\
\hline CULT4 & & & 0.88 & & & \\
\hline CULT5 & & & 0.845 & & & \\
\hline CULT6 & & & 0.845 & & & \\
\hline CULT7 & & & $\mathbf{0 . 4 3 6}$ & & & \\
\hline CULT8 & & & 0.853 & & & \\
\hline CULT9 & & & 0.748 & & & \\
\hline
\end{tabular}


Innovation Indicators and Growth in the United Arab Emirates

Table 3

Factor Analysis Results for Habitat

\begin{tabular}{|l|l|l|l|c|l|l|}
\cline { 2 - 7 } \multicolumn{1}{c|}{} & Resources & Attitude & Culture & Habitat & Imagination & Knowledge \\
\hline HABIT18 & & & & 0.838 & & \\
\hline HABIT19 & & & & 0.752 & & \\
\hline HABIT20 & & & & $\mathbf{0 . 6 9 7}$ & & \\
\hline HABIT21 & & & & 0.716 & & \\
\hline HABIT22 & & & & 0.809 & & \\
\hline HABIT23 & & & & 0.751 & & \\
\hline HABIT24 & & & & 0.817 & & \\
\hline HABIT25 & & & & $\mathbf{0 . 4 9 5}$ & & \\
\hline HABIT26 & & & & 0.807 & & \\
\hline HABIT27 & & & & 0.792 & & \\
\hline
\end{tabular}

Table 4

Correlation Between the Six Innovation Engine Components

\begin{tabular}{|c|c|c|c|c|c|c|}
\cline { 2 - 7 } \multicolumn{1}{c|}{} & Resources & Attitude & Culture & Habitat & Imagination & Knowledge \\
\hline Resources & 1 & & & & & \\
\hline Attitude & 0.827 & 1 & & & & \\
\hline Culture & 0.786 & $\mathbf{0 . 8 4 7}$ & 1 & & & \\
\hline Habitat & 0.949 & 0.85 & 0.811 & 1 & & \\
\hline Imagination & 0.673 & 0.732 & 0.677 & $\mathbf{0 . 6 9 6}$ & 1 & \\
\hline Knowledge & $\mathbf{0 . 8 0 8}$ & 0.874 & 0.834 & 0.842 & 0.743 & $\mathbf{1}$ \\
\hline
\end{tabular}

Although the sample size was not large, we still needed to check the reliability of the data. We checked the reliability using PLS, yielding a Cronbach's alpha threshold of .7, shown in Table 5. Cronbach's alpha far exceeded the threshold level of .7, indicating that the data were collected appropriately and from an adequate population.

Table 5

Reliability Test

\begin{tabular}{|c|c|c|c|c|}
\cline { 2 - 5 } \multicolumn{1}{c|}{} & $\begin{array}{c}\text { Cronbach's } \\
\text { alpha }\end{array}$ & rho_A & $\begin{array}{c}\text { Composite } \\
\text { reliability }\end{array}$ & $\begin{array}{c}\text { Average } \\
\text { Variance } \\
\text { Extracted (AVE) }\end{array}$ \\
\hline Resources & 0.895 & 0.9 & 0.918 & 0.615 \\
\hline Attitude & 0.875 & 0.885 & 0.898 & $\mathbf{0 . 4 2 8}$ \\
\hline Culture & 0.933 & 0.947 & 0.946 & 0.667 \\
\hline Habitat & 0.925 & 0.937 & 0.936 & 0.572 \\
\hline Imagination & 1 & 1 & 1 & 1 \\
\hline Knowledge & 0.865 & 0.88 & 0.895 & 0.52 \\
\hline
\end{tabular}




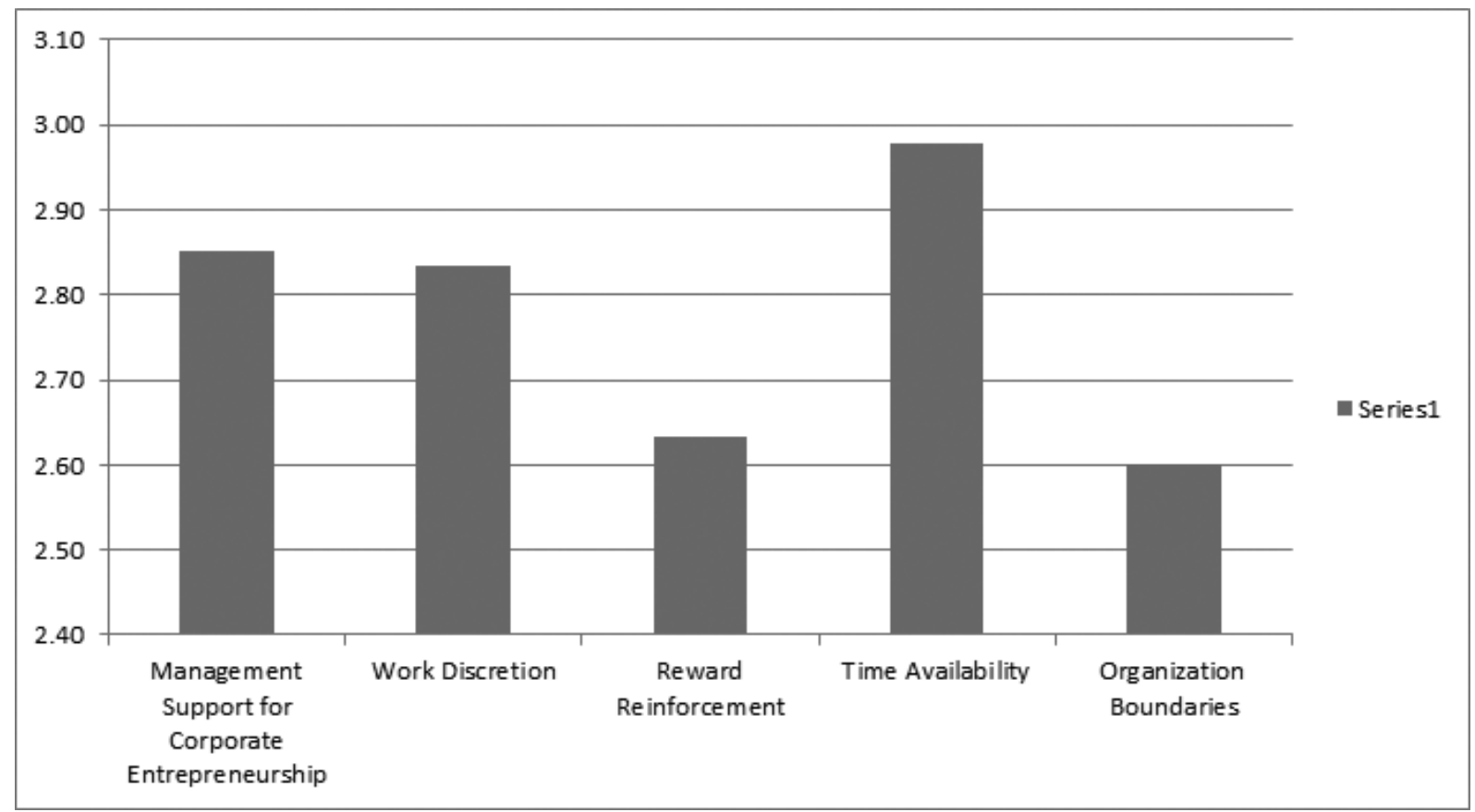

Figure 4. CEAI results from the UAE organizations survey.

Figure 4 shows results from the CEAI survey sampled in UAE organizations: The threshold level is three. We noticed that none of the five components is above three, explaining that the corporate-entrepreneurship culture has not yet reached the goal and also explaining that innovation leadership is not in place, even though organizations have set the Innovation Engine platform adequately in place.

\section{Conclusions}

Each of the Innovation Engine components correlates to questions generated by the CEAI questionnaire. Based on the data collected, UAE organizations do provide a decent innovation platform for innovation, where employees have some leeway to be innovative. However, on the entrepreneurial side, the threshold level is three, indicated by the CEAI, signifying that none of the five components has surpassed the threshold level. This result explains a lack of continuity in innovative ideas and that UAE organizations rarely pioneer new ideas. Thus, organizational leadership adopts no leadership style that will facilitate the development of fruitful innovative ideas.

Additional research needs to be done in this area. A larger survey embracing different types of organizations will increase the credibility of this study. Trifecta platform future research should focus on entrepreneurship and leadership adoption. 


\section{References}

1. Abou-Zeid, E. S., \& Cheng, Q. (2004). The effectiveness of innovation: A knowledge management approach. International Journal of Innovation Management, 8, 261-274. doi:10.1142/S1363919604001052

2. Amabile, T. M. (1988). A model of creativity and innovation in organizations. Research in Organizational Behavior, 10, 123-167. Retrieved from http://web.mit.edu/curhan/www

3. /docs/Articles/15341_Readings/Group_Performance/Amabile_A_Model_of

4. _CreativityOrg.Beh_v10_pp123-167.pdf

5. Ancona, D., \& Caldwell, D. (1987). Management issues facing new product teams in high technology companies. In D. Lewin, D. B. Lipsky, \& D. Sockell (Eds.), Advances in Industrial and Labor Relations (pp. 191-221). Greenwich, CT: JAI Press.

6. Anderson, N., Potočnik, K., \& Zhou, J. (2014). Innovation and creativity in organizations: A state-of-the-science review, prospective commentary, and guiding framework. Journal of Management, 40, 1297-1333. doi:10.1177/0149206314527128

7. Bornemann, M., Graggober, M., Hartlieb, E., Humpl, B., Koronakis, P., Primus, A., ... Willfort, R. (2003). An illustrated guide to knowledge management. Retrieved from http:// wm

8. -forum.org/files/2014/01/An_Illustrated_Guide_to_Knowledge_Management.pdf

9. Cantner, U., Joel, K., \& Schmidt, T. (2011). The effects of knowledge management on innovative success-An empirical analysis of German firms. Research Policy, 40, 14531462. doi:10.1016/j.respol.2011.06.007

10. Choi, J. N., \& Chang, J. Y. (2009). Innovation implementation in the public sector: An integration of institutional and collective dynamics. Journal of Applied Psychology, 94, 245-253. doi:10.1037/a0012994

11. Damanpour, F., \& Schneider, M. (2006). Phases of the adoption of innovation in organizations: Effects of environment, organization and top managers. British Journal of Management, 17, 215-236. doi:10.1111/j.1467-8551.2006.00498.x

12. Day, G. S. (1994). The capabilities of market-driven organizations. Journal of Marketing, 58(4), 37-52. doi:10.2307/1251915

13. Frambach, R. T., \& Schillewaert, N. (2002). Organizational innovation adoption: A multilevel framework of determinants and opportunities for future research. Journal of Business Research, 55, 163-176. doi:10.1016/S0148-2963(00)00152-1

14. Gopalakrishnan, S., \& Damanpour, F. (1994). Patterns of generation and adoption of innovation in organizations: Contingency models of innovation attributes. Journal of Engineering and Technology Management, 11(2), 95-116. doi:10.1016/09234748(94)90001-9

15. Hargadon, A. B., \& Bechky, B. A. (2006). When collections of creatives become creative collectives: A field study of problem solving at work. Organization Science, 17, 484-500. doi:10.1287/orsc.1060.0200

16. Katz, B., \& Du Preez, N. (2008). The role of knowledge management in supporting a radical innovation project. In A. Bernard \& S. Tichkiewitch (Eds.), Methods and tools for effective knowledge life-cycle-management (pp. 331-345). Berlin, Germany: Springer. doi:10.1007/978-3-540-78431-9_18

17. Klingebiel, R., \& Rammer, C. (2011). Resource allocation flexibility for innovation 
performance: The effects of breadth, uncertainty, and selectiveness (ZEW Discussion Paper No. 11-073). Mannheim, Germany: Center for European Economic Research.

18. Kör, B., \& Maden, C. (2013). The relationship between knowledge management and innovation in Turkish service and high-tech firms. International Journal of Business and Social Science, 4(4), 293-304. Retrieved from http://ijbssnet.com/journals/Vol_4_No_4_ April_2013/30.pdf

19. Pai, F. Y., \& Chang, H. F. (2013). The effects of knowledge sharing and absorption on organizational innovation performance-A dynamic capabilities perspective. Interdisciplinary Journal of Information, Knowledge, and Management, 8, 83-97. Retrieved from https://pdfs.semanticscholar.org/bac4/cf68b827f606446be847029f8216106880bc.pdf

20. Pavlou, P. A., \& El Sawy, O. A. (2006). From IT leveraging competence to competitive advantage in turbulent environments: The case of new product development. Information Systems Research, 17, 198-227. doi:10.1287/isre.1060.0094

21. Sarros, J. C., Cooper, B. K., \& Santora, J. C. (2008). Building a climate for innovation through transformational leadership and organizational culture. Journal of Leadership \& Organizational Studies, 15(2), 145-158.

22. Schumpeter, J. A. (1934). The theory of economic development: An inquiry into profits, capital, credit, interest, and the business cycle (R. Opie, Trans.). Piscataway, NJ: Transaction.

23. Shalley, C. E., \& Zhou, J. (2008). Organizational creativity research: A historical overview. In C. E. Shalley \& J. Zhou (Eds.), Handbook of organizational creativity (pp. 3-31). Hillsdale, NJ: Lawrence Erlbaum.

24. Srivastava, M. K., \& Gnyawali, D. R. (2011). When do relational resources matter? Leveraging portfolio technological resources for breakthrough innovation. Academy of Management Journal, 54, 797-810. doi:10.5465/AMJ.2011.64870140

25. Teece, D. J. (1986). Profiting from technological innovation: Implications for integration, collaboration, licensing and public policy. Research policy, 15(6), 285-305.

26. Turró, A., Urbano, D., \& Peris-Ortiz, M. (2014). Culture and innovation: The moderating effect of cultural values on corporate entrepreneurship. Technological Forecasting \& Social Change, 88, 360-369. doi:10.1016/j.techfore.2013.10.004

27. Yukl, G. (2002). Leadership in organizations (5th ed.). Upper Saddle River, NJ: Prentice Hall. 